\title{
Potential Gene Therapy for Intervertebral Disc Degeneration
}

\author{
Kotaro Nishida, Koichiro Maeno, Kakutani Kenichiro, \\ Takashi Yurube, and Masahiro Kurosaka \\ Department of Orthopaedic Surgery, \\ Kobe University Graduate School of Medicine \\ Kobe, \\ Japan
}

\section{Introduction}

Degenerative spinal disorders including low back pain are one of the most common and costly problems for modern society. It has been recognized that these disorders are directly or indirectly associated with intervertebral disc degeneration. The disc is a cartilaginous connective tissue, composed of the nucleus pulposus(NP), annulus fibrosus and endplates, which connects adjacent vertebrae (the functional spinal unit) and plays major roles in promoting the flexibility and stability of the lumbar spine. The NP is comprised of chondrocytic cells (nucleus pulposus cells) in an extensive extra-cellular matrix such as proteoglycan or collagen. Large molecules of proteoglycan exist in collagen networks and the high osmotic pressure produced by proteoglycan can result in inbibing water into the encapsulated NP, leading to high positive pressure inside the disc (Nachemson et al., 1970). The maintainance of this high positive presure inside of the disc is important in ensuring the biomechanical strength of the disc (Figure 1).

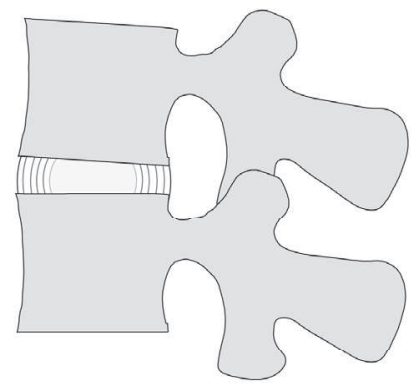

Functional Spinal Unit (FSU)

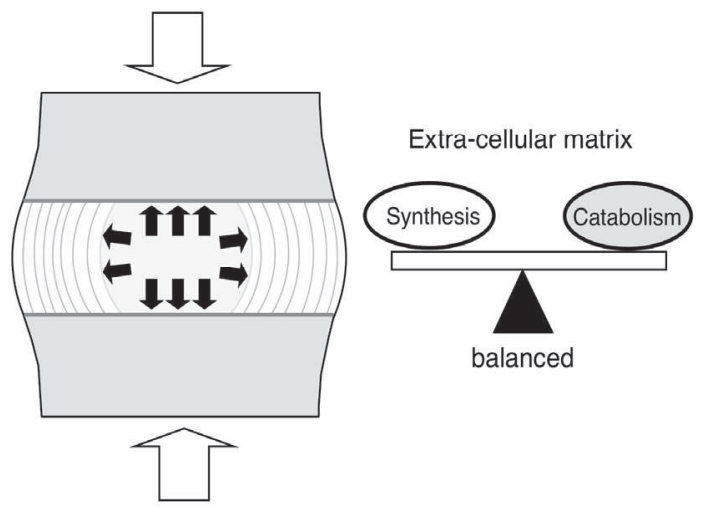

Fig. 1. Functional spinal unit and the biomechanical stability of the normal disc. 
In the process of disc degeneration, the loss of an important extra-cellular matrix such as proteoglycan leading to loss of water from the nucleus pulposus, results in loss of the biomechenical stability of the disc. In this process, since the capability for regeneration of the degenerated disc is very limited, clinical treatment of degenerative disc disorders, especially if there is mechanical instability in this segment, often necessitates removal of the degenerated disc and fusion of this segment (spinal fusion) with or without metal instruments (Figure 2). Spinal fusion has been one of the main surgical treatments for degenerative disc disorders with acceptable clinical results. However, there are several problems associated with spinal fusion surgery, such as accerelated degeneration in the disc adjacent to the fused segnment (Lee, 1988), breakage of instruments and damage to the nerve tissue during the instumentation procedure (West et al., 1991). In addition, the procedure is highly invasive, costly, and the risc of infection is comparatively high.

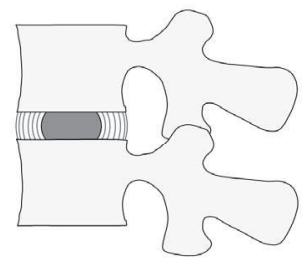

Phase 1: dysfunction

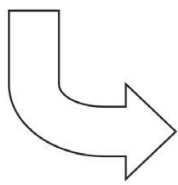

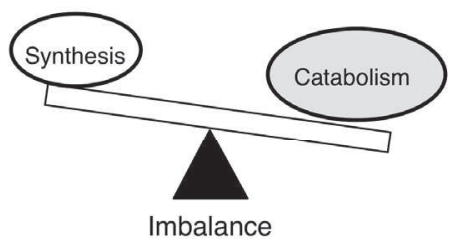

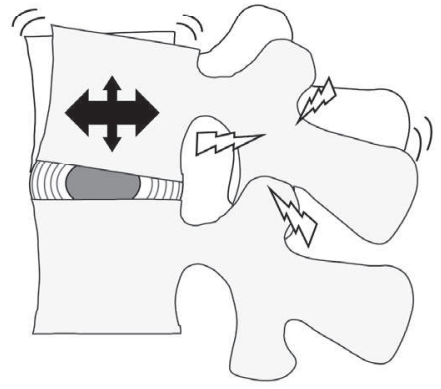

Phase 2: unstable

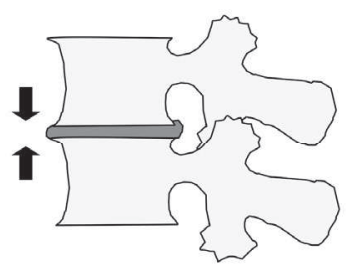

Phase 3: re-stabilization

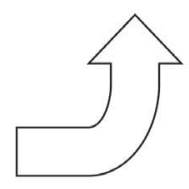

Fig. 2. Theoretical disc degeneration process (Kirkaldy \& Farfan, 1982).

To overcome these problems attention has recently turned to biological treatment methods in an effort to stimulate the regeneration process of the degenerated discs. Due to the relatively well encapsulated and avascular enviroment of the disc, it seems preferable to deliver bioactive materials into the disc to obtain positive biological effects which can maintain or regenearate disc tissue. Biological treatment for the degenerated disc can be divided into three major categories: 1) growth factor injection with or without a carrier, 2) cell transplantation including stem cells, and 3) gene therapy. However, it is clear that the disc has unique anatomical and physiological properties, which challenge many traditional biological approaches. Therefore, we discuss the possiblity of biological treatment approaches especially from the view point of delivery of molecular materials to the disc. One of the most significant advantages of gene therapy may be the sustained biological effect making it potentially suitable in the treatment of chronic diseases such as spinal disorders, particularly those disorders associated with disc degeneration. 


\section{Intradiscal gene therapy}

\subsection{Previously reported intradiscal gene therapy}

In vitro gene therapy approaches for the disc were first reported in 1997 and in vivo approaches in 1998. Attempts at intradiscal gene therapy using viral vectors have been made; however, due to the potential risks associated with viral gene therapy, the non-virus mediated intradiscal gene transfer method has been developed (see later discussion).

\subsubsection{Virus vector-mediated intradiscal gene therapy}

In 1997, Wehling et al. reported gene transfer to the chondrocytic cells from bovine intervertebral endplates using retrovirus vector in vitro (Wehling et al., 1997). This was the first report of gene therapy targeting the disc in vitro, and the authors indicated the potential use of indirect, ex vivo gene therapy for the degenerated disc by re-injecting genetically modified chondrocytic end-plate cells into the disc or surrounding tissue.

In 1998, Nishida and Kang et al. reported intradiscal direct gene transfer to the disc using an adenoviral vector in vivo with a rabbit model. This report was recognised as the first gene therapy approach targeting nucleus pulposus cells in vitro and in vivo. In their report, reporter gene expression continued in vivo at a seemingly undiminished level for at least 12 weeks. Later, their follow-up report using two different reporter genes showed the longevity of the transgene expression extended over 1 year. The results of these reports suggested that the adenoviral vector might be suitable for delivery of therapeutic genes to the disc, using an in vivo, direct gene therapy approach for the treatment of spinal disorders. In their next study, Nishida and Kang et al. reported an in vivo study using the rabbit model once again to determine the feasibility of the adenovirus-mediated transfer of a therapeutic gene to the intervertebral disc. They used an adenovirus construct containing a human transforming growth factor-beta1 (TGF-beta1) encoding gene (Ad/CMV-TGF beta1). In vivo injection of Ad/CMV-TGF beta 1 into the normal nucleus pulposus was revealed to result in an approximately six-fold increase in total (i.e., active + latent) TGF- beta 1 production over that of the intact control discs. The discs of the therapeutic gene group exhibited a statistically significant two-fold increase in proteoglycan synthesis compared to the intact control discs. This study demonstrated the efficacy of adenovirus-mediated transfer of a therapeutic gene to the intervertebral disc in vivo. The observation of a significant increase in proteoglycan synthesis secondary to gene transfer suggested that gene therapy might have potential applications in changing the time-course of degenerative disc disease.

Recently, Liang et al. reported the successful curative effects of gene therapy for the treatment of the degenerated disc in a novel mice model by adenoviral mediation of the human growth and differentiation factor-5 (GDF-5) gene (Liang et al., 2010). Their study confirmed the long-term expression of the target protein in the disc in vivo and also demonstrated the physiological improvements occurring in the disc.

Meanwhile, Lattermann et al. reported adeno-associated virus (AAV) vector-mediated gene transfer to intervertebral disc in vivo (Lattermann et al., 2005). AAV vectors are understood to be less immunogenic than adenoviral vectors and as yet have not been linked with any disease in humans or mammals. The overall transgene expression was approximately half of that seen with the adenovirus, and the in vivo gene expression was associated with a 4-6 week latency period. They concluded that due to safety concerns over the use of adenoviral vectors for human gene therapy, the AAV vector might offer a valuable alternative to the adenovirus as a delivery vehicle for therapeutic gene transfer into the intervertebral disc. 
Liu et al. reported the usefulness of baculovirus for the disc (Liu et al., 2006). Baculovirus is an insect virus able to deliver exogenous genes to mammalian cells including nondividing cells with no cell toxicity in vitro or in vivo. They concluded that baculovirus could transfer exogenous genes into rabbit nucleus pulposus cells safely and with high efficiency both in vitro and in vivo.

\subsubsection{Nonvirus vector-mediated intradiscal gene therapy}

Although the development of more sophisticated viral vectors such as non-toxic and safer vectors is still being investigated, progress in intradiscal gene therapy has been delayed by worries over the safety and potential costs of using recombinant viral vectors. Therefore, a number of non-virus mediated gene transfer techniques have been developed. However, the lower transfection efficiency compared with viral vector-mediated methods has been a major limitations of the non-virus mediated method, making the in vivo, direct gene transfer approach infeasible.

In 2006, Nishida et al. reported the efficacy of so-called "microbubble-enhanced ultrasound gene therapy" to the disc. More recent evidence suggested an appropriate intensity of ultrasound exposure could make a small transient hole on the cell membrane in a phenomenon called sonoporation, without causing cell toxicity. Additionally, it was reported that a kind of ultrasonography contrast agent called "micro-bubble" makes a cavitation with the exposure of ultrasound and this results in the bursting of the microbubbles leading to a distribution of material over a specific area of interest. Both these phenomenon, sonoporation and cavitation, are thought to have synergistic effects for increased transfection efficiency (Lawrie et al., 1999, 2000).

They demonstrated this micro-bubble enhanced ultrasound gene therapy in the intervertebral disc in vivo using a rat model. In their study, two different reporter plasmid DNA were used. They discovered that the ultrasound group demonstrated approximately an 11-fold increase in transgene expression over the plasmid DNA-only group. Moreover, transgene expression mediated by this method was seen, at least up to 24 weeks. These results demonstrate that ultrasound-mediated destruction of microbubbles loaded with plasmid-DNA is a feasible and efficient technique for local gene delivery within the intervertebral disc.

\subsection{New strategy for intradiscal gene therapy}

Despite much research effort, the successful biological treatment of degenerated discs is still limited to the injury induced disc degeneration (stub injury) model using relatively small animals. There are considerable limitations arising from the unique anatomy and physiology of the disc.

\subsubsection{Limitations of biological approaches for degenerated disc}

The lumbar intervertebral disc is known to be the largest avascular organ in the human body and the main path of nutrition or oxygen supply is passive diffusion via the endplates, resulting in poor nutrition and low oxygen tension, especially near the center of the disc (Grunhagen et al., 2006). Therefore, the metabolism in this area has to be relatively anaerobic, leading to the production of lactate, which in turn produces low $\mathrm{pH}$ inside of the disc (Nachemson, 1969). Low nutrition and oxygen tension, low $\mathrm{pH}$, and high positive pressure make the interior of the intervertebral disc a harsh biological environment. 
Therefore, NP cells existing in this environment must be highly differentiated to survive, which results in relative stability in terms of cell proliferation. Moreover, probably due to the low nutrition supply, the NP has a very low cell number compared with the rich extracellular matrix and a significantly low cellular metabolism.

Up to now, the main focus of intradiscal gene therapy and growth factor injection or cell therapy approaches has been to stimulate matrix synthesis. However, when taking the disc environment into consideration, methods requiring more resources or energy to up-regulate or stimulate matrix synthesis as well as cell proliferation seem less likely to result in successful disc regeneration. For successful biological treatment, taking into consideration of the characteristics of the target organ/tissue, and careful selection of the treatment strategy is necessary. As such, a different approach requiring less energy or fewer resources may have a better chance of promoting disc regeneration.

One of these approaches is the down-regulation of gene expressions that are potentially harmful for the physiological condition of the disc, and thus may induce degenerative change in the disc. This kind of approach focuses more on prophylactic treatment of disc degeneration. However, theoretically, it could become a regenerative treatment over an extended period (Figure 3). RNA interference (RNAi) is known to be a powerful means of sequence-specific gene silencing and would thus be a good candidate for this new strategy.

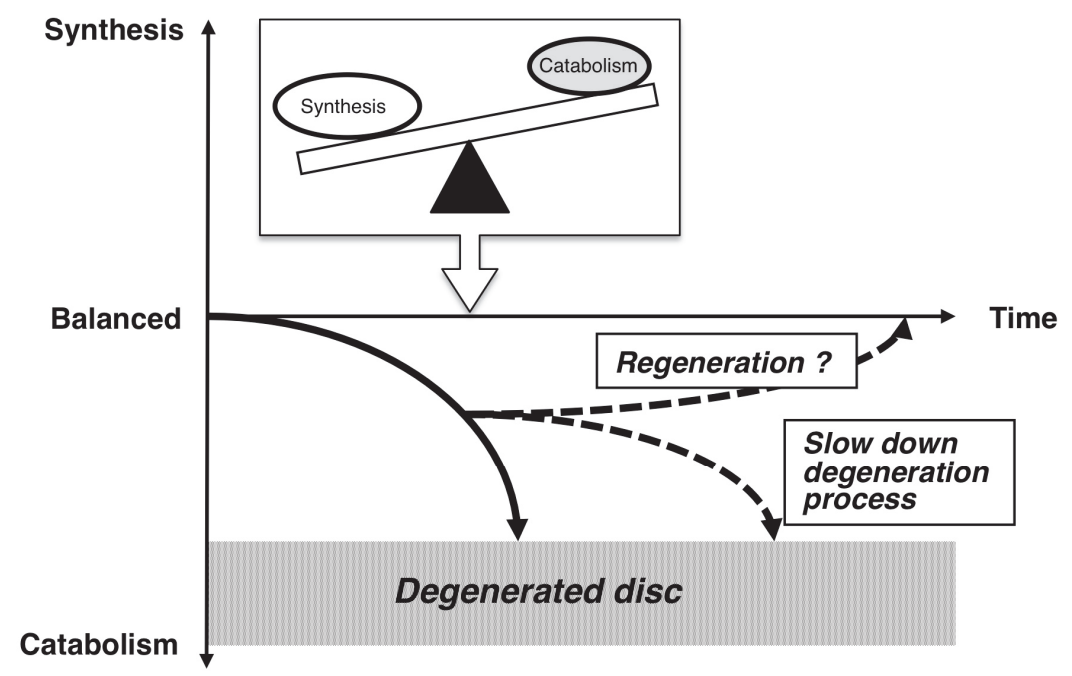

Fig. 3. Theoretical effect of continuous down regulation of catabolism by RNAi.

\subsubsection{Potential application of RNA interference for treatment degenerated disc associated disorders}

RNAi was first reported in 1998 by Fire et al. who demonstrated that double-stranded RNA induced sequence-specific silencing of gene expression in nematode cells (Fire et al., 1998). Elbashir et al. demonstrated that RNAi can be achieved in mammalian cells using oligoribonucleotide duplex 21 or 22 bases in length (small interfering RNA; siRNA) 
(Elbashir et al., 2001). Since then, a numbers of RNAi applications for a variety of organs/diseases have been intensively investigated.

In 2006, Kakutani and Nishida et al. reported for the first time that RNAi targeting exogenous reporter gene is effective in silencing transgene expression in nucleus pulposus cells in humans and rats in vitro. In their study, two reporter luciferase plasmids (Firefly and Renilla) were used. These plasmids were co-transfected with siRNA targeting Firefly luciferase to the nucleus pulposus cells extracted from rats and scoliosis patients. The inhibitory effects were evaluated by dual luciferase assay for 3 weeks. The results showed the expression of Firefly Luciferase was drastically inhibited both in rats $(94.7 \%)$ and in humans $(93.7 \%)$. These inhibitory effects continued for 3 weeks. The study thus demonstrated that siRNA-mediated gene silencing in rat and human disc cells in vitro is feasible and effective in down regulating specific gene expression.

In their follow-up study, Suzuki and Nishida et al. reported the effectiveness of the DNA vector-based RNAi technique in vitro for a prolonged RNAi effect. Furthermore, they demonstrated the simple unmodified siRNA-mediated RNAi effect in intervertebral discs in vivo (rat coccygeal discs) resulted in a prolonged period of up to 24 weeks (168 days). Additionally, this study demonstrated long-term down-regulation is possible not only for the exogenous reporter gene, but also for the endogenous gene (Fas ligand) expression in rat discs in vivo. As a result of the prolonged silencing effect after a single intradiscal transduction of unmodified siRNA, this gene delivery method is suitable as a local therapy for disc degeneration and associated disorders by down-regulating some harmful genes for the normal physiology of the disc, which may cause disc degeneration. (Figure 4)

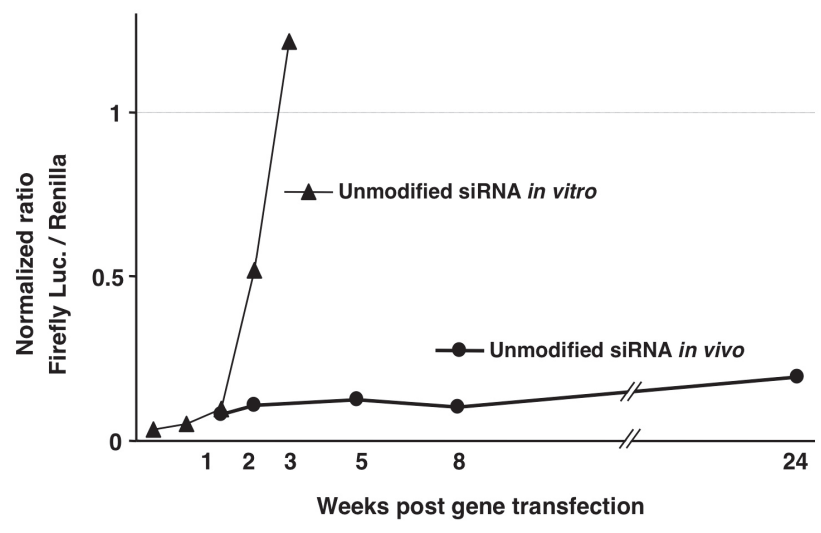

Fig. 4. Long-term RNAi effect mediated by unmodified siRNA in the nucleus pulposus in vivo (Modified from Suzuki et al., 2009).

More recently, Sudo and Minami reported successful RNAi in the degenerative process of the disc by down regulating Apotosis related factor caspase 3 (Sudo \& Minami, 2011). In their report, they investigated the effects of siRNA targeting caspase 3 on rabbit nucleus pulposus (NP) cells in vitro. The researchers concluded that these findings indicated caspase 3 knockdown in intervertebral disc cells is effective in preventing apoptotic cell death, and thus could regulate intervertebral disc degeneration. 


\section{Conclusion}

The gene therapy approach for the degenerated disc initially used a viral vector to transfer genes to stimulate important matrix synthesis for the disc such as proteoglycan. However, due to problems associated with a virus vector, a non-virus mediated gene transfer technique has been explored while the development of more sophisticated virus vectors remain a subject of investigation.

The difficulties of disc regeneration using a biological approach originate from the unique anatomical and physiological character of the disc. However, if we disregard these specific properties and the associated limitations of the disc, there may be little chance for successful regeneration. The successful treatment strategy for osteoporosis patients suggests us that the down-regulation of catabolic factors may be a more suitable strategy especially for organs/tissues with low cell metabolism and extensive extra-cellular matrix including bone or interverteral disc. As such, RNAi has been applied to the disc to down-regulate catabolic factors in the disc and correct imbalance between anabolic and catabolic factors with minimal nutrition requirements. This kind of approach would focus more on prophylactic treatment of disc degeneration. However, the potential exists for it to become a regenerative treatment over an extended period.

There are many issues to be overcome before the clinical use of RNAi can be permitted in patients suffering from degenerated discs and associated diseases. However, the demonstration that siRNA transfected by a nonvirus-mediated method can effectively inhibit specific gene expression in nucleus pulposus cells in vivo for an extended period lead the way for the exploration of siRNA as a novel strategy in gene therapy for the treatment of disc degeneration and associated diseases.

\section{Acknowledgment}

The authors thank Mrs. Tubby for their help in preparing the manuscript. Partial of this work was supported by Grant-in-Aid for Scientific Research (B) (19300184 and 21300189) from the Ministry of Education, Culture, Sports, Science and Technology of Japan.

\section{References}

Elbashir, SM., Harborth, J., Lendeckel, W., Yalcin, A., Weber, K., \& Tuschl, T. (2001). Duplexes of 21-nucleotide RNAs mediate RNA interference in cultured mammalian cells. Nature, Vol. 411, pp. 494-8

Fire, A., Xu, S., Montgomery, MK., Kostas, SA., Driver, SE., \& Mello, CC. (1998). Potent and specific genetic interference by double-stranded RNA in Caenorhabditis elegans. Nature, Vol. 391, pp.806-11

Grunhagen, T., Wilde, G., Soukane, DM., Shirazi-Adl, SA., \& Urban, JP. (2006). Nutrient supply and intervertebral disc metabolism. J Bone Joint Surg, Vol. 88-A, pp. 30-35

Kirkaldy-Willis, W. \& Farfan, H. (1982). Instability of the lumbar spine. Clin Orthop Relat Res, Vol. 165, pp. 110-23

Lattermann, C., Oxner, WM., Xiao, X., Li, J., Gilbertson, LG., Robbins, PD., \& Kang JD. (2005). The adeno associated viral vector as a strategy for intradiscal gene transfer in immune competent and pre-exposed rabbits. Spine, Vol. 30, pp. 497-504

Lawrie, A., Brisken, AF., Francis, SE., Tayler, DI., Chamberlain, J., Crossman, DC., Cumberland, DC., \& Newman, CM. (1999). Ultrasound enhances reporter gene 
expression after transfection of vascular cells in vitro. Circulation, Vol. 99, pp. 261720

Lawrie, A., Brisken, AF., Francis, SE., Cumberland, DC., Crossman, DC., \& Newman, CM. (2000). Microbubble-enhanced ultrasound for vascular gene delivery. Gene Ther, Vol. 7, pp. 2023-27

Lee, CK. (1988). Accelerated degeneration of the segment adjacent to a lumbar fusion. Spine, Vol. 13, pp. 375-7

Liang, H., Ma, SH., Feng, G., Shen FH., \& Li, XJ. (2010). Therapeutic effects of adenovirusmediated growth and differentiation factor- 5 in a mice disc degeneration model induced by annulus needle puncture. Spine J, Vol. 10, pp. 32-41

Liu, X., Li, K., Song, J., Liang, C., Wang, X., \& Chen, X. (2006). Efficient and stable gene expression in rabbit intervertebral disc cells transduced with a recombinant baculovirus vector. Spine, Vol. 31, pp. 732-35

Nachemson, A. \& Elfstrom, G. (1970). Intravital dynamic pressure measurements in lumbar discs: a study of common movements, maneuvers and exercises. Scand J Rehabil Med Suppl, Vol. 1, pp. 1- 40

Nachemson, A. (1969). Intradiscal measurements of $\mathrm{pH}$ in patients with lumbar rhizopathies. Acta Orthop Scand, Vol. 40, pp. 23-42

Sudo, H. \& Minami, A. Caspase 3 as a thrapeutic target for regulation of intervertebral disc degeneration. (2011). Arthritis Rheum, Jan 21, doi:10.1002/art.30251. [Epub ahead of print]

Wehling, P., Schulitz, KP., Robbins, PD., Evans, CH., \& Reinecke, JA. (1997). Transfer of genes to chondrocytic cells of the lumbar spine. Proposal for a treatment strategy of spinal disorders by local gene therapy. Spine, Vol. 22, pp.1092-97

West, JL., Ogilvie, JW., Bradford, DS. (1991). Complications of variable screw plate pedicle screw fixation. Spine, Vol. 16, pp. 576-9 


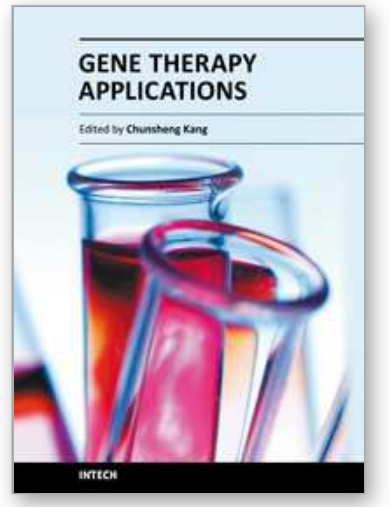

\author{
Gene Therapy Applications \\ Edited by Prof. Chunsheng Kang
}

ISBN 978-953-307-541-9

Hard cover, 492 pages

Publisher InTech

Published online 23, August, 2011

Published in print edition August, 2011

The aim of our book is to provide a detailed discussion of gene therapy application in human diseases. The book brings together major approaches: (1) Gene therapy in blood and vascular system, (2) Gene therapy in orthopedics, (3) Gene therapy in genitourinary system, (4) Gene therapy in other diseases. This source will make clinicians and researchers comfortable with the potential and problems of gene therapy application.

\title{
How to reference
}

In order to correctly reference this scholarly work, feel free to copy and paste the following:

Kotaro Nishida, Koichiro Maeno, Kakutani Kenichiro, Takashi Yurube, and Masahiro Kurosaka (2011).

Potential Gene Therapy for Intervertebral Disc Degeneration, Gene Therapy Applications, Prof. Chunsheng Kang (Ed.), ISBN: 978-953-307-541-9, InTech, Available from: http://www.intechopen.com/books/genetherapy-applications/potential-gene-therapy-for-intervertebral-disc-degeneration

\section{INTECH}

open science | open minds

\section{InTech Europe}

University Campus STeP Ri

Slavka Krautzeka 83/A

51000 Rijeka, Croatia

Phone: +385 (51) 770447

Fax: +385 (51) 686166

www.intechopen.com

\section{InTech China}

Unit 405, Office Block, Hotel Equatorial Shanghai

No.65, Yan An Road (West), Shanghai, 200040, China

中国上海市延安西路65号上海国际贵都大饭店办公楼 405 单元

Phone: +86-21-62489820

Fax: +86-21-62489821 
(C) 2011 The Author(s). Licensee IntechOpen. This chapter is distributed under the terms of the Creative Commons Attribution-NonCommercialShareAlike-3.0 License, which permits use, distribution and reproduction for non-commercial purposes, provided the original is properly cited and derivative works building on this content are distributed under the same license. 